\section{UJMM

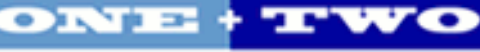

Volume 11 | 2021 Spring 2021

\section{Undergraduate Journal of Mathematical} Modeling: One + Two

2021

\title{
Analyzing Piney Point's Wastewater Discharge Rate
}

Josephina Reyman

University of South Florida

Advisors:

Arcadii Grinshpan, Mathematics and Statistics

Connie Mizak, School of Geosciences

Problem Suggested By: Connie Mizak

Follow this and additional works at: https://digitalcommons.usf.edu/ujmm

Part of the Mathematics Commons

UJMM is an open access journal, free to authors and readers, and relies on your support:

Donate Now

\section{Recommended Citation}

Reyman, Josephina (2021) "Analyzing Piney Point's Wastewater Discharge Rate," Undergraduate Journal of Mathematical Modeling: One + Two: Vol. 11: Iss. 2, Article 6.

DOI: https://doi.org/10.5038/2326-3652.11.2.4934

Available at: https://digitalcommons.usf.edu/ujmm/vol11/iss2/6 


\title{
Analyzing Piney Point's Wastewater Discharge Rate
}

\author{
Abstract \\ Implicit differentiation is used in order to find the cubic feet of water dumped into Tampa Bay per hour \\ from the Piney Point reservoir. To get to moles from cubic feet, a series of conversions is done while Le \\ Chatelier's principle explains how an increase in $\mathrm{HPO}_{4}{ }^{2-}$ (hydrogen phosphate) in Tampa Bay is going to \\ affect algae growth. The rate of moles of $\mathrm{HPO}_{4}{ }^{2-}$ is analyzed as well as the consequences that come \\ with dumping copious amounts of fertilizer water into an aquatic environment.
}

\section{Keywords}

aquatic ecosystem, hydrogen phosphate, algae growth, fertilizer water, red tide, discharge rate, Le Chatelier's principle

\section{Creative Commons License}

c.) (i) (2)

This work is licensed under a Creative Commons Attribution-Noncommercial-Share Alike 3.0 United States License. 


\section{Problem Statement}

Analyze the rate at which water from the Piney Point phosphate reservoir is flowing into Tampa Bay and determine its effects.

\section{Motivation}

Excess nutrients from fertilizer, such as phosphorous, have been known to ruin aquatic ecosystems through red tides caused by large algae blooms. In order for fertilizer to be made, phosphate rock is mined mostly by surface methods. Once the phosphates are mined, they are then taken to a processing plant to be converted into $\mathrm{HPO}^{2-}$ which is a necessary component for most fertilizers. The waste left behind from phosphate mining is known as phosphogypsum. Sacks of phosphogypsum are normally filled with fertilizer wastewater containing $\mathrm{HPO}^{2-}$ which creates a reservoir that prevents damage to surrounding ecosystems. On March 27, 2021 site operators at Piney Point in Manatee County, Florida noticed a leak coming from the site's largest wastewater reservoir (see Figure 1). The reservoir contained fertilizer wastewater from a closed phosphate plant. Before the leak started the reservoir contained almost 480 million gallons of wastewater. To keep the leak from flooding Manatee County, site operators began pumping water out of the reservoir into Tampa Bay. This is a serious issue as the contaminated water from the reservoir is likely to cause a red tide in Tampa Bay which would be detrimental to its marine ecosystem. The objective of this project is to determine how many moles of $\mathrm{HPO}^{2-}$ are being dumped into Tampa Bay per hour from Piney Point and the effects that could occur. 


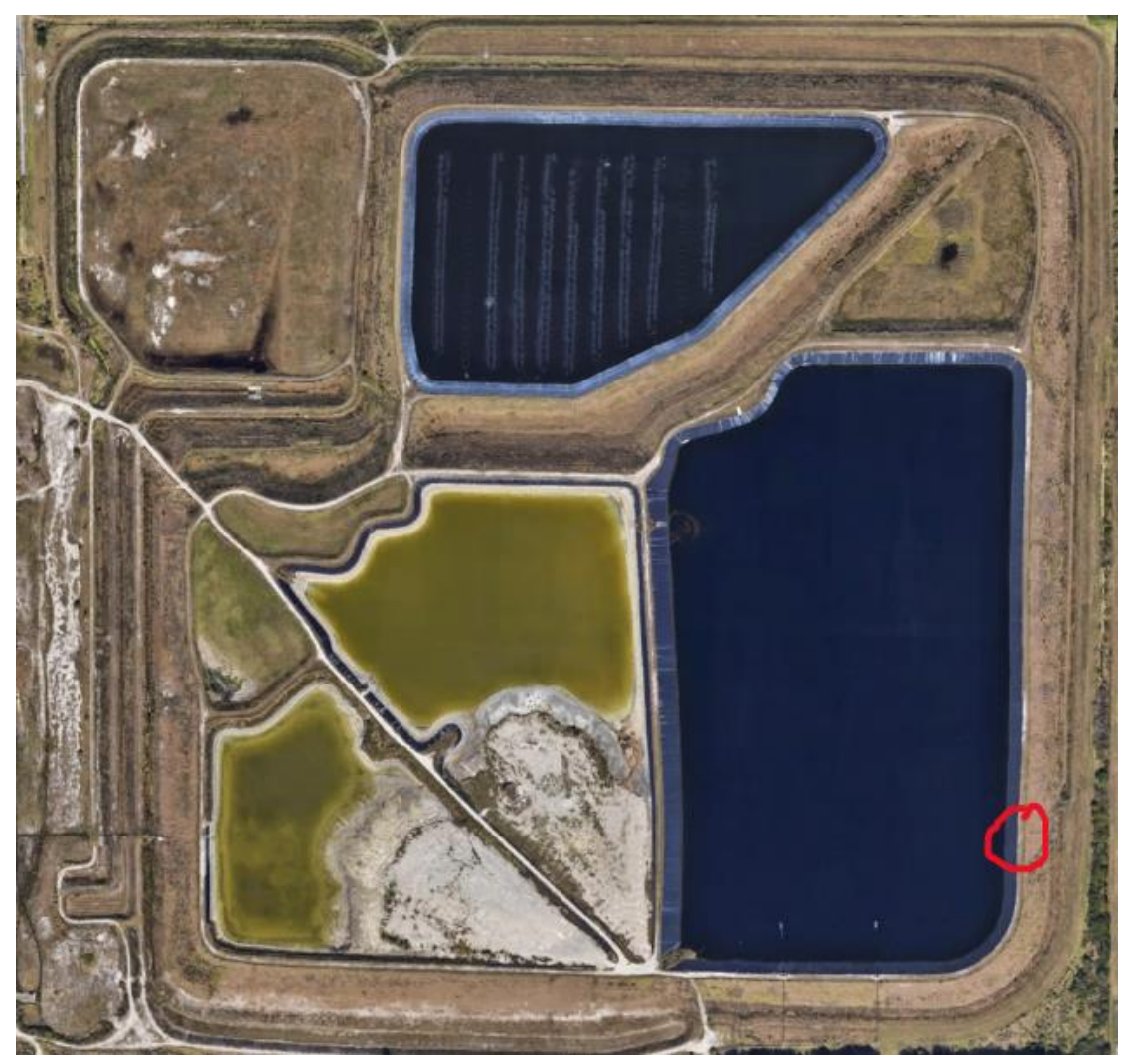

Figure 1. Google Earth image of leak location

\section{Mathematical Description and Solution Approach}

The dimensions of the leaking reservoir are 2370 feet long and 1410 feet wide with an original water height of 19.2 feet high. The total volume of the container is 64160640 cubic feet. The water height of the reservoir is decreasing at a rate of $0.05 \overline{3}$ feet per hour. The shape of the reservoir is a rectangular prism so in order to find the decreasing volume in cubic feet, the volume equation for a rectangular prism is needed and is as follows: 


$$
\boldsymbol{V}=\boldsymbol{L} \times \boldsymbol{w} \times \boldsymbol{h}
$$

2370 is then plugged into equation (1) as $L$ while 1410 is plugged in as $w$. The new volume equation (2) is:

$$
\begin{gathered}
V=2370 \times 1410 \times h \\
V=3341700 h
\end{gathered}
$$

Next, the derivatives of $V$ and $h$ are taken with respect to time:

$$
\frac{d V}{d t}=3341700 \frac{d h}{d t}
$$

Since the height is decreasing at $0.05 \overline{3}$ feet per hour, this will be the $\frac{d h}{d t}$ that can be substituted into equation (3). The volume is found in cubic feet, so it is multiplied by 7.481 to be converted into gallons. This gives the following:

$$
\begin{gathered}
\frac{d V}{d t}=3341700 \times 0.05 \overline{3}=178224 \\
\frac{178224 \mathrm{ft}^{3}}{1} \times \frac{7.481 \text { gallons }}{1 \text { ft }^{3}} \approx 1333293.7 \text { gallons per hour }
\end{gathered}
$$

Now that the rate of gallons of water flowing into Tampa Bay per hour is found to be 1333293.7, it needs to be converted to moles of $\mathrm{HPO}^{2-}$. USF researchers reported that dumping 100 million gallons of phosphate water into Tampa Bay from Piney Point is similar to depositing 50,000 of 50-pound bags of fertilizer into the bay. To calculate the bags of fertilizer, a proportion is set up where $B$ is equal to bags of fertilizer dumped per hour:

$$
\frac{50000}{100000000}=\frac{B}{1333293.7}
$$




$$
B=666.64685
$$

One 50-pound bag of fertilizer contains an average of 5 pounds of $\mathrm{HPO}^{2-}$. Once the pounds of $\mathrm{HPO}^{2-}$ are found, a conversion of bags to pounds to grams to moles is done and results in the following number of moles of $\mathrm{HPO}^{2-}$ being dumped into Tampa bay per hour:

$$
\begin{gathered}
\frac{666.64685 \mathrm{~B}}{1} \times \frac{5 \mathrm{lbs}}{1 \mathrm{~B}} \times \frac{453.592 \mathrm{~g} \mathrm{\textrm {HPO4 } ^ { 2 - }}}{1 \mathrm{lb}} \times \frac{1 \mathrm{~mol} \mathrm{HPO4}^{2-}}{95.979 \mathrm{~g} \mathrm{HPO4}^{2-}} \\
=15752.6999648 \mathrm{moles} \mathrm{HPO4}^{2-}
\end{gathered}
$$

\section{Discussion}

We found the moles of $\mathrm{HPO}^{2-}$, and will now use Le Chatelier's principle to describe the affects that our results could have on the Tampa Bay area. The following equation is used to show chemically how algae is formed:

$$
\begin{aligned}
124 \mathrm{CO}_{2}(\mathrm{~g})+ & 16 \mathrm{NO}_{3}^{-}(\mathrm{aq})+\mathrm{HPO4}^{2-}(\mathrm{aq})+140 \mathrm{H}_{2} \mathrm{O}(\mathrm{l}) \\
& \rightleftharpoons \mathrm{C}_{106} \mathrm{H}_{263} \mathrm{O}_{110} \mathrm{~N}_{16} \mathrm{P}(\mathrm{s})+138 \mathrm{O}_{2}(\mathrm{~g})+18 \mathrm{HCO}_{3}^{-}(\mathrm{g})
\end{aligned}
$$

Le Chatelier's principle states that when a system experiences a new stress, in this case an increase in reactants, it will shift to restore a new equilibrium state. It is important to note that the algae chemical reaction strongly favors the forward reaction over the reverse reaction; however, since equilibrium is being discussed, double arrows are used in equation (7). Figure 2 below gives a visual representation of the reaction quotient $Q_{c}$, in relation to the equilibrium constant, $K_{C}$. 


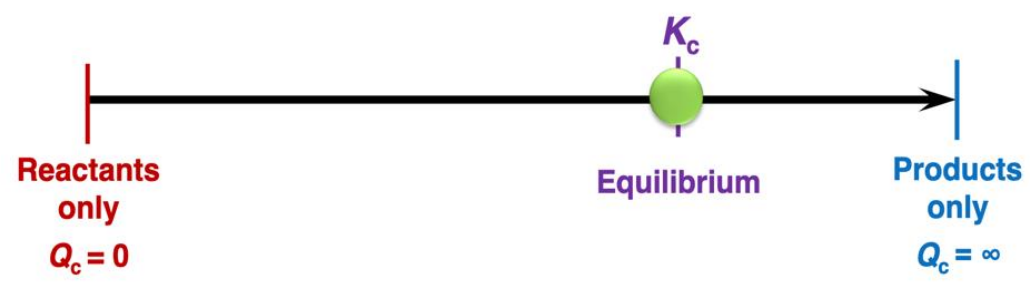

Figure 2. Representation of $K_{C}$ and $Q_{c}$

Originally, equation (7) shows $\mathrm{HPO}^{2-}$ on the reactants side where only one mole of hydrogen phosphate is required to make one mole of algae. The leak from the reservoir has increased the mole concentration of hydrogen phosphate to $\approx 15752.7$ moles per hour as calculated in equation (6). To compensate for the drastic increase in hydrogen phosphate, the reaction direction is going to shift towards the products side, or the right when looking at Figure 2. This shift will lead to an increase in algae production in order to use up the $\mathrm{HPO}^{2-}$ and get back to equilibrium leading to a possible red tide. If a red tide were to occur the fish populations and marine plant life populations would drop. The beaches near Tampa Bay would also close which would lead to a decrease in tourism. Overall, the significant increase in moles of $\mathrm{HPO}^{2-}$ per hour could be detrimental to Tampa Bay's economy as well as its marine ecosystem if a large algae bloom resulting in red tide were to occur.

Our objective to analyze the rate of wastewater being dumped into Tampa Bay from Piney Point has been met. We used implicit differentiation to find the decrease in cubic feet of the reservoir per hour. We then did several conversions to get from cubic feet to moles of $\mathrm{HPO}^{2-}$. 
Finally, we discussed how the moles of $\mathrm{HPO}^{2-}$ being deposited into Tampa bay would affect marine ecosystems as well as the Tampa Bay economy.

\section{Conclusion and Recommendations}

Our analysis shows that there is a significant amount of $\mathrm{HPO}^{2-}$ being dumped into Tampa Bay at an hourly rate. Our recommendation is for researchers to closely monitor where in the bay the $\mathrm{HPO}^{2-}$ is spreading. We would also recommend the fish populations and plant life populations be tracked.

The next important step would be calculating the molarity of the $\mathrm{HPO}^{2-}$. If the molarity were found, one would be able to determine the $\mathrm{PH}$ of the hydrogen phosphate solution. Research could then be done to determine the effect that the $\mathrm{HPO}^{2-} \mathrm{PH}$ would have on the PH of Tampa Bay's water. 


\section{Nomenclature}

\begin{tabular}{|c|c|}
\hline Symbol & Meaning \\
\hline$g$ & Grams \\
\hline moles & Moles \\
\hline$l b s$ & Pounds \\
\hline$V$ & Volume \\
\hline$L$ & Length \\
\hline$w$ & Width \\
\hline$h$ & Height \\
\hline$\frac{d V}{d t}$ & Derivative of volume with respect to time \\
\hline$\frac{d h}{d t}$ & Derivative of height with respect to time \\
\hline$B$ & Bags of fertilizer per hour \\
\hline$K_{C}$ & Equilibrium Constant \\
\hline$Q_{c}$ & Reaction Quotient \\
\hline
\end{tabular}




\section{References}

Costanza, Frankie. "Thursday 2/11: First Lecture for Exam 2." CHM 2046: General Chemistry 2, 11 Feb. 2021, University of South Florida, Tampa, FL. Lecture.

Ebeling, James M., et.al. "Engineering analysis of the stoichiometry of photoautotrophic, autotrophic, and heterotrophic removal of ammonia-nitrogen in aquaculture systems." Aquaculture, Volume 257, Issues 1-4, 2006, pp. 346-358, https://doi.org/10.1016/j.aquaculture.2006.03.019.

Henderson, Carl S., "Piney Point Phosphate Plant: An Environmental Analysis" (2004). USF St. Petersburg campus Honors Program Theses (Undergraduate). 63. https://digital.stpetersburg.usf.edu/honorstheses/63.

Simpson, Zachary T. “"50,000 Bags of Fertilizer': What Could Piney Point Do to Tampa Bay?” Tampa Bay Times, 5 Apr. 2021, www.tampabay.com/news/environment/2021/04/05/50000-bags-of-fertilizer-what-couldpiney-point-do-to-tampa-bay/. 